\title{
The impact of journal re-grading on perception of ranking systems: exploring the case of the academic journal guide and business and management scholars in the UK
}

Article

Accepted Version

Walker, J., Salter, A., Fontinha, R. and Salandra, R. (2019) The impact of journal re-grading on perception of ranking systems: exploring the case of the academic journal guide and business and management scholars in the UK. Research Evaluation, 28 (3). pp. 218-231. ISSN 1471-5449 doi: https://doi.org/10.1093/reseval/rvz010 Available at https://centaur.reading.ac.uk/83253/

It is advisable to refer to the publisher's version if you intend to cite from the work. See Guidance on citing.

To link to this article DOI: http://dx.doi.org/10.1093/reseval/rvz010

Publisher: Oxford Academic

All outputs in CentAUR are protected by Intellectual Property Rights law, including copyright law. Copyright and IPR is retained by the creators or other copyright holders. Terms and conditions for use of this material are defined in the End User Agreement. 


\section{www.reading.ac.uk/centaur}

\section{CentAUR}

Central Archive at the University of Reading

Reading's research outputs online 
The Impact of Journal Re-grading on Perception of Ranking Systems: Exploring the Case of the Academic Journal Guide and Business and Management Scholars in the UK

James T. Walker, International Business \& Strategy, Henley Business School at the University of Reading (corresponding author)

Ammon Salter, School of Management, University of Bath

Rita Fontinha, International Business \& Strategy, Henley Business School at the University of Reading

Rossella Salandra, School of Management, University of Bath

\begin{abstract}
The marked increase in the use of metrics, such as journal lists, to assess research has had a profound effect on academics' working lives. While some view the diffusion of rankings as beneficial, others consider their diffusion as a malicious development, which further acerbates a tendency towards managerialism in academia, and undermine the integrity and diversity of academic research. Using data from a largescale survey and a re-grading of journals in a ranking used by Business and Management UK scholars - the Academic Journal Guide (AJG) - as a pseudoexperiment, we examine what determines negative and positive perceptions of rankings. We find that the individuals who published in outlets that were upgraded were less hostile to the ranking than those who did not benefit from these changes, and that individuals were also less hostile to the ranking if outlets in their field had benefited from re-grading in the new list. We also find that the individuals who published in outlets that were upgraded were more positive to the ranking than those who did not benefit from these changes, and that individuals were also more positive to the ranking if outlets in their field had benefited from re-grading in the new list.
\end{abstract}

\title{
INTRODUCTION
}

Although academic roles include responsibilities in terms of teaching, research and administration (Kinman and Wray 2016; Tytherleight, Webb, Cooper and Ricketts 2005), research output is still one of the most prevalent measures of academic productivity (Dietz and Bozeman 2005), with relevant implications for career progression. For this reason, the way research outputs are assessed, such as through 
peer review, journal impact factors and journal rankings, has become a focal point of debate (Newton 2010). Over time, in the evaluation of research quality, there has been a shift internationally toward the more extensive use of metric-based appraisal methods, which are often embedded in other forms of evaluation such as research assessment exercises (Jappelli et al. 2017). Moreover, these lists and metrics have been integrated with many teaching-related and institutional ranking systems, inducing a range of possible effects on knowledge production and the daily practice of doing research (Rijcke et al. 2016).

Given this shift, there is a widely held perception that metrics and journal lists have become an invasive part in academic life, which has in turn led to critical scrutiny of these metrics and lists. Many authors have pointed to the limitations of journal impact factors, ranging from the effects of the different coverage of journals across time (Mañana-Rodríguez 2015) to the skew in the number of citations to papers in a journal, which make these measures unreliable guides to the 'quality' of outputs (Baum 2011). As a result, there has been a call for the use of 'responsible metrics', including the 'Leiden Manifesto' that proposes a set of guidelines about the use of metrics (Hicks et al. 2015). In that debate, particular attention has been focused on journal rankings. It has been suggested that the use of these lists, or ranking systems, is leading to a sort of 'list fetishism' in which the content of the paper assumes less importance than the journal it is published in (e.g. Hussain 2015; Mingers and Willmott 2013; Willmott 2011). Researchers have argued that journal lists influence the research of academics by limiting the diversity of methods and topics used and thereby restricting innovation and critical appraisal (e.g., Adler and Harzing 2009; Alvesson and Sandberg 2013; Lawrence, 2008; Macdonald and Kam 2007; Northcott and Linacre 2010). 
On the other hand, researchers have argued that journal lists can also provide benefits to individual academics by assisting them in obtaining recognition for their work and evaluating the work of colleagues within their own and other fields (BadenFuller et al 2000; Morris et al. 2010; Morris et al. 2011). In addition, recent research has found that journals that are highly ranked are more supportive of interdisciplinary and innovative work, but they publish more quantitative methods in comparison to lower ranked journals (Vogel, et al. 2017). Furthermore, it has been argued that lists provide decision makers with valuable information to be able to make efficient decisions about research quality, thereby aiding in activities such as promotions and hiring, resource allocation and research evaluation exercises (Agrawal et al. 2011; Beattie and Goodacre 2012; Giles and Garand, 2007; Reinstein and Calderon 2006; Voss 2010).

Regardless of whether individuals manifest hostility or are positively inclined towards rankings, as Gioia and Corley (2002: 115) pragmatically point out "we need to start with the premise: The rankings are not going away." Moreover, these journal ranking systems can and do change, and these changes may in turn shape the way individuals view the ranking systems. Indeed, there is a question about whether changes in journal ranking systems themselves elicit greater hostility or whether they are more positively viewed by some individuals based upon the nature of these changes. We address individual's positive vs. negative views of rankings following changes in the rankings by focusing on the expectancy theory (Vroom 1964; Porter and Lawler 1968), which suggests that individuals expect a certain valued reward based on their performance. When individuals are over-rewarded they tend to experience less cognitive dissonance towards the system and more satisfaction (Pritchard et al. 1972), than when they are under-rewarded. This leads us to the 
question: Are individuals' views of ranking systems sensitive to changes that benefit (or damage) their own portfolio of publications? Furthermore, we aim to investigate individuals' opinions when changes in the ranking do not affect them directly, but do affect their peers. We focus on social identity theory (Tajfel and Turner 1979), where social identification with one group is likely to help shape attitudes towards specific elements that may affect the group (Ashforth and Mael 1989) and try to answer the question: Are individuals' views of ranking systems affected by changes impacting upon their research field?

In order to address these questions, we use a pseudo-experimental approach exploiting the effects of an exogenous regrading of a journal ranking of individuals' publication outlets and journals in their respective fields. We use the context of faculty working at business schools in the United Kingdom (UK), who are subject to a recurring national research assessment system, what is called the Research Excellence Framework (REF). The REF rewards research performance with funding, primarily on the basis of publications. Although the UK's REF is based on peer review, most UK business schools have adopted a journal list, the Academic Journal Guide (AJG), ${ }^{1}$ to inform their decision-making about the value of different research outputs, and have embedded the AJG in their workload, hiring and probationary systems. The AJG was originally developed by the Association of Business Schools and has been updated in waves over the past 10 years. The AJG itself is based on a mixture of metrics and expert assessment. It attempts to offer a comprehensive list of journals for business and management schools ranked by the 'rigour, significance and originality' of their outputs. The AJG 2015 included some 1,401 journals (Academic Journal Guide 2015).

\footnotetext{
${ }^{1}$ The AJG is widely known at the "ABS list", but its name was formally changed in 2015 .
} 
Although the AJG list is one of a number of internationally available journal rankings for business and management, it is by far the most extensively used list among UK business schools, with over 89 per cent of academics working in business schools in the UK indicating they use the AJG in their professional roles (Walker et al. 2018). The AJG is also used outside the UK: according to the publishers of the AJG, the Charter Association of Business Schools (CABS), US-based academics are the second largest set of users of the list.

To explore our research questions, we utilize five different sources of data, including information collated from websites, a large-scale survey of academics, data from the UK national research evaluation exercise, journal ranking information, and individuals' publication records in Scopus. We find that individuals who published in outlets that were upgraded were more positive/less hostile to the ranking, and were also more positive/less hostile if their field had benefited from re-grading in the new list.

\section{RESEARCH EVALUATION IN UK BUSINESS SCHOOLS}

Business and Management is an important cognate area for research evaluations, as the large size of business schools relative to other university departments has led them to be subject to considerable pressure for enhanced performance by academic institutions (Piercy 2000). Business and management schools are also subject to many high-profile rankings, many of which primarily focused on teaching but also incorporate research. For example, the Financial Times ranking of MBA programs relies primarily on the salary gains of graduates, but also on the number of papers produced by faculty in a proscribed list of journals. Furthermore, the use of journal lists has become a common tool utilised in research evaluation in Business and Management. Harzing (2018) maintains a regularly updated 'list of lists', 
consolidating rankings of journals in Business and Management used in variety of countries, including Australia, Denmark, and France among others.

Although subject to many international rankings, the UK context is a particularly appropriate setting for understanding attitudes to journal rankings as it has a relatively homogenous higher education system with a long history of research assessment (Collini 2008; Hicks 2012). Furthermore, concerns about the use of metrics have been consistently raised in the UK (Harman 2000; Ball and Butler 2004; Chatterji and Seaman 2006; Macdonald and Kam 2007; Broadbent 2010). At the institutional level, research in the UK is evaluated via publicly funded 'research selectivity exercises', collectively known as the Research Excellence Framework (REF), which have recently seen the introduction of impact assessment (Khazragui and Hudson 2014; Williams and Grant 2018). The outcomes of these exercises are published at the unit of assessment or subject level, such as 'Business and Management', where individuals' research outputs grades are aggregated. The REF is important to business schools as both a direct source of government research funding, and an indirect source of status and reputation.

Within the REF, research performance is assessed at the institutional level, and therefore, in order to decide whether an individual's work is of sufficient quality to be entered into the exercise, business schools need to evaluate the quality of their own faculty. In an attempt to anticipate the decisions of the REF peer review process, institutions typically assess the quality of individual papers indirectly by evaluating the outlets in which they are published, making use of journal rankings. It is clear that in preparing their REF submissions, many institutions relied upon the Academic Journal Guide as a proxy for the sub-panel's likely assessment (By, Burnes, and Oswick 2013). Anecdotal evidence indicates that such an 'arm's length' appraisal 
process is now endemic in business schools for hiring, appraisal and promotion decisions (Agyemang and Broadbent 2015; De Rond and Miller, 2005; Macdonald and Kam 2007; Willmott 2011), which affords journal rankings an increasing degree of importance. Table 1 summarizes the key features of these two related systems (i.e. the REF and the AJG).

\section{--- Insert Table 1 here ---}

Over time, there has been a substantive fall in the number of staff submitted by UK business schools in the national research assessment, indicating greater selectivity in determining who will be considered for the assessment. Indeed, between the 2008 and the 2014 assessment, the percentage of all eligible staff submitted fell from 95 per cent to about 47 per cent. This shift can also be discerned via the data provided from the two recent assessments: the RAE (2008) and REF (2014). Using information from the ABS 2010, the version of the academic journal list that was the last to appear before REF 2014, Table 2 highlights the shift towards AJG 3 and 4-star ranked outputs between RAE 2008 and REF 2014. The extent of the change is substantive and reinforces survey evidence linking the views of staff to the appreciation that the journal guide had a powerful role in determining which outputs and which individuals were submitted to the REF 2014.

\section{--- Insert Table 2 here ---}

Given the extensive use of the AJG and its impact on the lives of faculty, it is perhaps not surprising that it has been controversial, as some individuals view it positively, while others direct considerable hostility to it. Although the use of lists can help researchers obtain recognition for their work (Baden-Fuller et al. 2000; Morris et al. 2010; Morris et al. 2011) and it may reward interdisciplinary and innovative papers (Vogel et al. 2017), the use of the AJG has been argued to generate a type of 
'list fetishism' whereby the journal's rank is given prominence over the content of the paper (e.g. Hussain 2015; Mingers and Willmott 2013; Willmott 2011). Concerns that the list has explicit and implicit biases have also been raised in a series of studies (e.g. Hoepner and Unerman, 2012; Hussain, 2011, Morris et al., 2011; Findlay and Sparks 2010; Stewart 2005).

Despite these controversies, to date there has been little research examining attitudes to the use of lists by academics. Surveys of league tables and rankings have tended to focus upon the views of senior managers (see Hazelcorn, 2007, 2008, 2009). Walker et al. (2018) suggest that lists are used more extensively by those individuals with strong positive or negative views about them.

As it stands, these prior studies have tended to treat journal ranking systems and attitudes towards them as fixed, yet these ranking systems do themselves change. These changes may emerge in response to external pressures and/or through incorporation of new information. As yet, there is little or no research on how changes in journal rankings may influence individuals' views about these systems. Are individuals sensitive to these variations, especially if they gain (or lose) from changes in the ranking system? Do such changes lead to more favourable views or feelings of greater hostility to the ranking system itself?

\section{HYPOTHESES}

\section{Social Justification, Expectations and Attitudes towards the AJG}

Given that the AJG plays a pervasive role in shaping the working lives of UK business and management academics, we rely on social cognitive theories and previous empirical findings in order to establish hypotheses regarding the main antecedents of views towards the list. One element that may influence academics' opinions about the AJG is a change in the ranking of a journal where they have 
published. The AJG was updated in 2015, meaning that a journal's position in the rank may have improved, worsened or remained unchanged compared to the previous ranking: while several journals had a positive change in the ranking, for others there was a negative change. Individuals were able to examine the rates and compare these directly from the prior rankings as the list provides the most recent ranking alongside prior rankings. These changes may represent either an over-fulfilment or a breach of business academics' expectations.

According to the expectancy theory of motivation articulated by Vroom (1964), later expanded by Porter and Lawler (1968), individuals are motivated to choose a certain behaviour over other behaviours based upon what they expect the result will be. This theory has been applied to explain the main antecedents of individual performance in organisations (e.g. Bunderson and Sutcliffe 2002; Lepine, Podsakoff and Lepine 2005) and employees' attitudes toward performance management and reward systems (Perry, Engbers and Jun 2009). Expectancy theory has also been used to explain the research productivity of business faculty members, suggesting that where a high value is attributed to both intrinsic and extrinsic rewards, this leads to a higher research productivity (Chen, Gupta and Hoshower 2006). We now address expectancy theory in order to explain academics' attitudes towards the AJG.

Expectancy theory has three components: expectancy, instrumentality, and valence. Expectancy consists of a belief that individual's effort will lead to the attainment of desired performance goals; instrumentality represents the belief that if the performance expectation is met that person will be rewarded; and valence refers to the value the individual attributes to the rewards (Vroom 1964). When a business academic publishes a paper in an AJG ranked journal, particularly a highly ranked 
one, he/she is likely to perceive that his/her effort was rewarded, and that reward that may have an important valence for his/her career. If a journal's position in the ranking changes in their favour, business academics' careers may be benefited, meaning that one's intended effort to publish in a journal was over-rewarded. This may result in a more positive opinion of the AJG ranking. This assumption would be consistent with previous empirical evidence suggesting that individuals who are over-rewarded tend to experience less cognitive dissonance towards the system and more satisfaction (Pritchard et al. 1972), with nuances depending on aspects such as their equity sensitivity (Allen, Evans and White 2011) and on their perceived fairness and selfinterest (Peeters and van den Bos 2008). In contrast, when there is a negative change in the ranking of a journal where they published before, business academics are likely to perceive that the initial reward for their effort was now taken away: the rules of the game changed, which may be considered unfair. In terms of valence, the downgrade of a journal on the AJG may have important repercussions in terms of the measurement of their productivity (Dietz and Bozeman 2005) and related career progression and employability. Given that the new 'rules of the game' are now less favourable to them, meaning that they were under-rewarded, they are likely to have more hostile opinions of the AJG.

H1: When there is a positive (negative) change in the ranking of journals where an individual has previously published then that individual is more likely to be more favourable (or more hostile) towards the ranking system.

Although a change in the ranking of a journal where a business academic has published in the past may shape their current attitudes, it is possible that a positive or negative change in the ranking of journals in the field where an academic is active may also influence his/her opinion about the ranking. In this particular case, the 
expectancy theory framework (Vroom 1964), suggesting that an individual is motivated to perform based on an expected reward with a high valence, can explain this rationale when combined with some ideas deriving from the social identity theory (Tajfel and Turner 1979). Social identification is a perception of "oneness" with a group of people, which leads to activities that are consistent with the identity, support for institutions or others that embody that identity. By frequently publishing in a specific field within the AJG ranking (e.g., Finance, International Business and Area Studies, Marketing, etc.), business academics may perceive themselves to be part of a group with shared interests (Ashforth and Mael 1989). Social identification with a particular in-group is likely to help shape attitudes towards specific elements that may affect the group. In the context of higher education in the UK, previous evidence suggests that there are individual and collective values central to academic identity, namely the primacy of the discipline (Henkel 2005), suggesting that academics are likely to perceive a specific field or discipline as an in-group. A change in the ranking of journals in the field affects the in-group they belong to, which may help shape their attitudes towards the AJG. Applying expectancy theory and the rationale developed for the previous hypothesis to an in-group/out-group identity context, we hypothesise:

H2: When there is a positive (negative) change in the ranking of journals in an individual's field, that individual is more likely to be more favourable (or more hostile) towards the ranking system.

\section{METHODS}

\section{Setting, Data and Sample}

Our setting is drawn from the UK business and management education sector, which is home to a large and diverse set of institutions. Some of these business and management schools have been operating for over 50 years, whereas others are 
relatively new. Typically, business and management schools emerged out of existing universities, but there are several 'stand-alone' institutions, such as London Business School. Almost all of the UK business schools are public, charitable institutions, with a core mission of education, teaching and outreach. The average size of school is around 70 faculty, with the largest being Manchester Business School with 220 faculty. Funding for business and management schools is largely drawn from student fees, with research income providing only a modest share of total revenue. Over the past 20 years, these schools have seen impressive growth as a result of increased enrolments at undergraduate and graduate levels. The number of full-time equivalent faculty employed by the sector increased from 9,300 in 2004 to 12,300 in $2015 .^{2}$

Faculty in these institutions are generally employed on traditional academic contracts, which in the UK context implies an open-ended contract after completing probation. Although these open-ended contracts are similar to tenure, they do not provide the same degree of permanence as North American contacts, as faculty are liable to be subject to significant performance reviews. Depending on the practices of each institution, 'poor' performance, especially with regard to research, may lead to re-contracting into a teaching or adjunct roles, or even in some cases redundancy.

Another key feature of the UK system is a high level of labour mobility between institutions. This is partly due to the homogeneity of the system as well as the transferability of the pensions. In addition, and particularly in the lead up to the national research assessment, there are often opportunities for individuals to better their personal circumstances by moving, bringing with them 'their' outputs to enhance their employers' REF submission.

\footnotetext{
${ }^{2}$ Figures taken from HESA statistics, https://www.hesa.ac.uk/services/heidi-plus, accessed in May 2018 .
} 
In this context, the ABS list was initially developed as a list of all the journals that had three or more articles submitted to the Business and Management unit of assessment panel of the RAE in 2001. Further journals were then added following a comparison with alternative lists from six UK business schools (Morris et al. 2010). The original ABS list reduced the importance of institution specific lists by explicitly consolidating them and drawing upon the "expert opinion" of scholars representing fields within business and management and metric information, with those experts being given access to citation-based metric information provided by methodologists.

Four versions of the guide were produced by the same editorial team prior to 2010. The 2010 ranking included 825 journals distributed across 22 fields, where journals were ranked between one and four, with the fourth and highest category distinguishing between four graded journals and elite so-called 'Journals of Distinction'. However, the new version, published in 2015, marked a major development of the list. In governance terms, the entire editorial board and all but two of members of expert advisory team who are responsible for putting forward rankings the rankings were replaced. Furthermore, the expert advisory group grew significantly increasing from 12 to 33 . The guide was re-titled AJG to reflect a less UK-based focus. The methodology used provided information on longer run citation information normalized within each of the newly defined 22 sub-disciplines and their associated ranking. In addition, subject specialists engaged in a process of examining journals in their fields. This, coupled with a call for journal editors to apply for incorporation of the list, saw the list grow by more than 40 per cent to include 1,401 journals. The revision process led to 223 journal ranking changes, including 180 upgrades and 43 downgrades. These changes accounted for 16 per cent of all the journals on the 2015 list and 27 per cent of all journals on the 2010 list, indicating the re-grading exercise 
was substantive. The decision to upgrade and downgrade these journals was taken by the ABS list Scientific Committee with guidance from its subject matter experts, combining data provided by the methodologists and their own evaluation of journals based on their specific knowledge areas and via consultation from field experts. The final decisions were not communicated outside the ABS list Scientific Committee and methodologists, who retained the editorial responsibility for the list. Although subject-matter experts may have been consulted on some of these re-grading decisions, they were asked to not disclose any information about their part of the list prior to its final publication.

We focus on the population of academics working at UK business schools in the period immediately following the REF 2014. Along with information from the AJG itself, our research approach involves combining information from five independent sources: 1. websites of business schools; 2. results of the RAE/REF census; 3 . individuals' publication data; 4. journal ranking information, and 5. a large-scale survey.

The initial stage of the data collection involved collating information from universities' websites on the faculty working in business schools in the UK, including their rank and gender. These details were gathered at three points in time -1 . immediately prior to the 2014 REF census at the end of $2013 ; 2$. the following year at which time email addresses were also recorded; and 3. a final update in 2015, when all researchers' names and contact details were re-checked via websites to make sure that they were as accurate and current as possible. The second information source was the REF census and outcomes, which is published by the Higher Education Funding Council of England. These data include unit of assessment scores from the REF, along with individual research outputs. The third source of information captured 
individual-level faculty publication information that were compiled from Elsevier's Scopus and downloaded in July 2014. We used Scopus over other bibliometric databases due to the ease of its author search and its extensive coverage of business and management research. These data were manually checked before being further cross-checked using information from websites and other sources.

The fifth element in our study was a large-scale survey. The survey data used in this study come from a wider research project exploring business academics views of the journal lists that was conducted in 2015. The study involved administering an online questionnaire to all academics working in business schools who had participated in RAE 2008 with the addition of University College London. We focused our survey on those individuals who were likely to be 'research active' in their employment contracts, and therefore the sample included Senior Teaching fellows but excluded Teaching Associates/Teaching fellows as well as Honorary, Visiting, Emeritus scholars. The final population comprised 8,002 academics, affiliated to 90 business and management schools in the UK.

The survey was designed using an iterative approach. We started by bringing together questions from prior research on ranking lists, before developing a bespoke set of questions. The initial draft of the survey was then piloted using more than 20 business and management academics, the majority of which were based outside the UK but had had recent experience of working at UK universities. In response to the pilots, we redrafted the text of the questions and then ran the redrafted pilots with a group of business school faculty. The survey was live for one month, and we asked non-respondents to participate three times during this period. The survey received 1,945 responses, generating a response rate of around 24 per cent. 
We carried out several tests of the population to check the reliability of the survey responses against potential sources of bias in our sample. First, we investigated if there was any difference in the typology of the university that respondents were affiliated to, compared to the rest of the sample: we performed a non-parametric test and found no significant differences. Second, we compared the ranks of respondents to the overall sample, separating institutions' ranking in the REF using their overall Grade Point Average (GPA). The sample has a slightly greater proportion of professors and a higher share of staff from the top 20 research-oriented institutions, due to the exclusion of teaching fellows from our wider sample. In order to check for non-response bias between the waves we tested whether there were differences in the responses between the early and late respondents but found no statistically significant differences (Van der Stede, et al. 2005). Finally, we checked the primary expertise of survey participants as a means to suggest a reasonable correspondence between participants and those who had been submitted to REF 2014 . In order to do so, the proportion of REF outputs was compared to the primary expertise of participants who completed the survey using the subject classifications provided by AJG 2015. Overall, the sample was consistent with the outputs that had been submitted to the REF. Having excluded responses for non-item response and completing matching across the five sources of data, we were left with a sample of 1,409 to analyse.

\section{Measures}

\section{Dependent variable}

The survey had a number questions enabling participants to provide their views of the AJG. Specifically, participants were asked to provide their level of agreement [using a five-point scale listing 1. 'Strongly Disagree', 2. 'Disagree', 3. 'Sometimes', 
4. 'Agree', 5. 'Strongly Agree'] with the following negative statements derived from a systematic review of the literature - 'The Academic Journal Guide/ABS list: "Shifts research efforts away from debates that researchers would like to contribute to", "Fosters a 'research monoculture", "Encourages researchers to focus on issues that are only of interest to other academics rather than practitioners/policy-makers", "Promotes 'low risk' research", "Leads to technically well-executed but boring research", "Rewards journals that strive to 'imitate a US-oriented model of scholarship"' (e.g. Hussain 2015; Mingers and Willmott 2013; Willmott 2011; Hoepner and Unerman 2012; Hussain 2011; Morris et al., 2011; Findlay and Sparks 2010; Stewart 2005). To ensure that participants did not tick down the list, they were also asked a number of neutral or positive statements such as whether the AJG "Encourages academics to be more targeted in where they publish their research", "Helps researchers to make judgments about the quality of research being undertaken by a researcher in their field". This questionnaire design strategy is consistent with the recommendations of Podsakoff et al. (2003). We also utilized principal component analysis to derive the variables used in the analysis. Principal component analysis' results enabled us to test for the convergent validity of our set of used variables and discriminate them from the positively worded items. To derive the dependent variable, negative views (hostility), we take the arithmetic mean of the negative items. Motivated by research conducted by Landis, Beal and Tesluk (2000), we take the mean score across the seven categories to capture the hostility to the of the list. Reliability was also tested for using the Cronbach alpha $(\alpha=0.87)$. We take an analogous approach to derive positive views (positively inclined towards) using the Cronbach alpha $(\alpha=0.84)$. 
In order to provide an initial examination of whether, and the extent to which, academics are hostile or positively inclined toward the AJG, Table 3 provides summary statistics for the dependent variables (with the five-point being simplified into three groups for expositional purposes). It highlights the degree of positivity vs. hostility to the AJG across different questions with the majority agreeing or strongly agreeing that the AJG is detrimental to scholarship (between 46.6 and 72.0 per cent or 62.2 on average) and a significant minority being in disagreement (between 10.1 and 20.7 per cent). In contrast, between 41.4 and 68.4 (or 50.9 per cent on average) agreed or strongly agreed that the AJG was positive to scholarship, while a more substantial minority, between 10.9 and 35.1(or 26.7 per cent), disagreed or strongly disagreed.

--- Insert Table 3 here ---

\section{Independent variables}

Changes in rankings. The reclassification of the ABS list to the AJG list led to changes in ranking of journals and in individual subject areas across differing ranks. We classify shifts from 2 to 3 -star ("New" 3), from 3 to 2-star ("Old" 3), from 3 to 4 star ("New" 4), from 4 to 3-star ("Old" 4) for each individual creating count variables that capture the number of changes experienced.

Change in field. The AJG classifies journals into 22 subject areas and the reclassification had uneven effects on different fields. There was variation in the proportion of output classified in the AJG as being 4-star in the revision compared to the prior ranking (omitting the focal individual). For example, the Management Development and Education field, which had no 4-star outlets, upgraded Academy of Management Learning and Education from 3-star. Some areas were expanded with a number of new entries, such as Economics, which had five journals upgraded. Others, such as General Management, Ethics and Social Responsibility had no net gains with 
one journal being added, Business Ethics Quarterly, while another journal, the Harvard Business Review, was downgraded to a three. The impact at the level of the field has also differed, sometimes substantively. For example, in the field of Operations and Technology, seven times more papers were published by scholars in our sample in the International Journal of Operations and Production Management, a journal re-graded from 3- to 4-star, than the only other 4-star outlet in the area, Production and Operations Management. In order to identify the individual's field, we asked respondents to self-report with the option of choosing 'other' if they considered that their field was not represented. Perhaps reflecting the development of the List, and the fact that a key distinctive feature of its development has been to align to and consult a broad set of disciplines often linked to academic associations and bodies, only 20 ( $1.3 \%$ of that sample) of the 1,429 faculty chose 'other'.

Using the publication data, we derive a change in field variable that captures changes within the field that the focal individual considers their primary field of expertise, to evaluate whether individuals whose fields benefited more greatly from the reclassification, by having a higher proportion of 3- or 4-star outputs after the reclassification. The survey asks individuals to identify their primary areas of expertise enabling us to align the changes in primary subject areas to individuals.

\section{Control variables}

Inclusion in the national research assessment exercise. An individual's inclusion in the national research assessment exercise (i.e. the REF) may shape their hostility to the AJG, as significant number of our respondents were not included in the REF by their institution. As a result, we included a variable that attempts to capture whether an individual was included in the national assessment. Although the REF results do not link individuals' names, they do provide sufficient information 
that has allowed us to do "fuzzy matching". This matching was done by careful manual checking by one of the authors in our team. Specifically, the REF provided information such as co-authorship, institution, in some cases research groups, and clustered individual's outputs. Using this approach, we were able to link publications to individuals in over 95 per cent of cases.

Academic influence. We included a variable for individual researchers' academic influence using the total number of citations recorded by Scopus.

Academic rank. We asked respondents "What is your current position?" and then generated three dummy variables professor, associate professor, and lecturer coded as 1 when respondents selected "Professor/Chair", "Associate Professor/Reader/Senior Lecturer/Senior Research Fellow/Principal Research Fellow" or "Lecturer/Assistant Professor/ Research Fellow/Research Associate" respectively. Where we did not have a response to this question, we took this information from the business schools' websites.

Gender. Using information on the business schools' websites, a dummy variable equal to 1 for male and 0 for female faculty was generated.

Academic age. Researchers' academic age was quantified as the years from their first publication.

Obtained PhD in North America. A dummy variable equal to 1 if the individuals were awarded their $\mathrm{PhD}$ from a US university and 0 otherwise was created. Our assumption was that North American trained scholars would have greater affinity to journal lists than those trained elsewhere, such as Europe, where such lists are a relatively new development. ${ }^{3}$

\footnotetext{
${ }^{3}$ Those trained in North America place a higher value on journal ranked on the list that others. In business and management research, the North American-based journals have traditionally held the strongest positions in journal rankings. Indeed, almost all of the 24 journals included in the UTDallas list, which is one of the main lists of top journals in the general field, are based in North America. The
} 
Alignment to the AJG. The AJG does not capture the full population of journals and so some individuals' research may be excluded from it. It is possible that individuals who have large proportions of their scholarly output excluded by the AJG may be liable to be hostile towards it. Thus, we controlled for individual's output that is published in outlets that are included in the AJG, measured from 0 to 100 per cent.

Overall rank of institution in $\mathrm{REF}$ 2014. To control for the research intensity of the school where the individual was employed, we used the Grade Point Average (GPA) of each institution that was computed from REF Summary for Unit of Assessment 19 - Business and Management.

Involved in construction of the AJG. We also capture whether survey participants were consulted in the construction of the AJG and therefore may be less hostile (or more positive) towards it. To do so, we included a variable on the survey focusing on the response to the question "Were you involved in the consultation process for the construction of the latest Academic Journal Guide?". Those who identify themselves as being involved in the process are coded as 1 and 0 otherwise.

Field. Field dummies are included to control for any field-level differences. On the survey, individuals were asked to declare their primary area of research using the main subjects listed in the AJG 2015, which covers 22 disciplinary areas.

\section{RESULTS}

FT50 list of journals also has a strong North American emphasis. European (including the UK) research communities tend to have more diffuse and diverse sets of outlets. Our assumption is that those individuals trained in the North American system would have a stronger imprint of norms and expectations about journal lists than their European trained cousins, who trained in an environment with less clear hierarchies and norms about outlets. Indeed, as a personal aside, two of the authors in our team were trained in the UK during the "pre-list era" and have little or no recollection of discussions or training in the specific hierarchies of journals in business and management during their doctoral programmes. 
Descriptive statistics of the main and control variables are reported in Table 4. Table 4 shows that the majority of the respondents (58 per cent) were male, and that all ranks of the academic ladder are represented in the sample. Fifty-four per cent of our respondents were included in the national research exercise, which is slightly higher than the population.

\section{--- Insert Table 4 here ---}

The descriptive data also highlight that the proportion of outputs that were upgraded was greater than that which was downgraded. Eighteen per cent of individuals in the sample benefited from the reclassification in 4-star papers ("New" 4), while only three per cent had a reduction ("Old" 4). It was also the case that 15 per cent of individuals had a paper in their portfolio that was re-graded from 2 to 3 -star ("New" 3), while nine per cent had at least one reduced in rank ("Old" 3).

Pairwise correlations between the dependent variables negative and positive views and explanatory variables are also provided. The correlations between explanatory variables are not particularly high. ${ }^{4}$

Table 5 reports the results using a Generalized Least Squares (GLS) estimator calculating and reporting marginal effects on what determines hostility to lists. ${ }^{5}$ Before turning to the key hypotheses, Model 1 incorporates a set of controls. As might have been expected, we find that those who were included in the REF were likely to be less negative about the journal ranking than those who were not. Model 2 introduces lifetime citations; the findings do not suggest that the scholars with higher academic influence have a stronger view "against" the AJG. We also find that women

\footnotetext{
4 Correlations between the field 22 dummies and other variables are omitted due to space considerations, but note that the correlations between these and other field level variables were not significant, with the exception of two, which were not high. While we prefer to use these as controls the results are not affected if they are omitted.

5 To ensure the robustness of our finding we also transformed the independent variable using logs to account for it being skewed. However, the p-values and the effect sizes did not change qualitatively using this alternative approach.
} 
have a more negative view of the list compared to men. In addition, individuals who had obtained a Ph.D. in North America have a substantially less negative view of the ranking, being over 40 per cent less hostile than those trained elsewhere. Of note, participants that had been involved in the consultation process for the construction of the AJG did not show a stronger predisposition either for or against the list as implied by the insignificant coefficient. That finding did not change when we excluded individuals who were directly involved in producing the list [i.e. the Scientific Advisors (Subject Experts) or Committee Members]. ${ }^{6}$ Nor do the results suggest that the institution in which individuals work influence views, after having controlled for individual's academic influence and other factors.

\section{--- Insert Table 5 here ---}

We turn now to the key hypotheses in Tables 5 and 6 . Hypothesis 1 anticipated that business academics' views of the AJG were influenced by the extent of an exogenous change in the rank of the journals where they had previously published. A rise in a paper in an individual's portfolio from 2 to 3 -star did not lead to individuals being more or less hostile to the journal rank. This may be related to the importance given to 4-star journals by university research managers, however consistent with our expectations, business academics whose papers have experienced an upward shift in journal ranking from a 3 to a 4 -star were less hostile (more positive) to the journal ranking than those whose papers kept the same position. We also found that a reduction from either 4 to 3 -star, or from 3 to 2 -star in journals where they have

\footnotetext{
${ }^{6}$ Advised by a referee, we have also analysed the robustness of the finding to examine whether the behaviour of those individuals directly involved in the development of the list - i.e. Scientific Advisors (Subject Experts) or Committee Members - differed from those who were involved indirectly typically by being consulted on the ranking. To do so we identified the individuals and who meet this criteria in a separate file with identifiers then being merged back into the data removing them from the "involved" group and creating a second binary variable "CABs Decision Maker". However, we did not find either variable was significantly $(\mathrm{z}=0.81$ for "CABs Decision Maker" and $\mathrm{z}=0.54$ for "Involved")."
} 
previously published does not influence business academics' views of the ranking either positively or negatively. Hence hypothesis 1 was partially supported.

--- Insert Table 6 here ---

Hypothesis 2 anticipated that business academics' views of the AJG were influenced by the extent of an exogenous change in journal rank in journals within their field. This hypothesis was supported. Table 5 illustrated that the marginal impact of that upward shift in the focal field is that it leads members of that academic community to be about four per cent less hostile to the journal list that those who work in other academic disciplines. Table 6 shows that the opposite is the case with respect to positively held views, and the coefficients are quite similar in magnitude to those reported in Table 5.

In order to examine whether the findings are robust to alternative measures of academic influence, we examined a different measure focusing on Scopus's Source Normalized Impact Factor (SNIP) journal impact ranking in models 2-5. We use the individual's SNIP Journal weighted outputs obtained from data from 2008-2012, the date that the data was last available prior to the REF process, and find this to be a more robust indicator. Given the highly skewed nature of citations, we break the variable into quartiles in Model 5. The findings suggest that there are substantive differences between researchers who publish in the top quartile of research output and those that do not.

It is the case that some fields are composites of distinct fields. The CABS field classified three areas that fall into this category, two because of their being broad areas - the General Management category that also combined ethics and CSR; Social Science that captured general journals in the social sciences that were not captured elsewhere in the list, such as in economics and "sector" that combined public sector 
and health journals. It could be argued that because these areas have less well defined boundaries than other fields, individuals within those composite fields may behave differently. To examine whether this was the case, Model 6 excludes these groups. The results do not suggest a material difference to the key findings.

Comparing the results in Table 5 and Table 6 one can observe that the key findings are highly consistent, but oppositely signed. There are, however, a number of differences in the control variables implying substantive asymmetries. In general, the control variables were less likely to be determinants of positive views. For example, while being trained in North America substantially reduced hostility (Table 5) it did not have a statistically well-defined relation with positive views (Table 6). While participants that had been involved in the consultation process for the construction of the AJG did not show to be hostile to the list (Table 5), they were positive about it (Table 6). Excluding individuals who were directly involved in producing the list [the Scientific Advisors (Subject Experts) or Committee Members] did not qualitatively alter the findings.

\section{CONCLUSIONS}

Our analysis of what drives individual's attitudes towards rankings indicates that researchers who benefit from changes in rankings through the re-grading of journals where they have published are less hostile/more positive than those researchers who did not benefit from these changes. This is consistent with the idea that individuals who are over-rewarded tend to experience more satisfaction, when compared to those who are under-rewarded (Pritchard et al., 1972). However, we found little evidence that individuals whose papers were downgraded in the ranking were more hostile/less 
positive to the list than those who did not suffer this outcome. This may arise from the fact that hostility among these individuals was already high and therefore a downgrade of their journals simply reinforced, rather than enhanced, their views.

Our results additionally suggest that individuals are less hostile/more positive to the ranking system when their field benefits from a positive re-ranking, which suggests some level of identity within a discipline (Henkel 2005) and shared interests (Ashforth and Mael 1989). The field of research as a proxy for group membership may reflect one of the multiple forms of commitment academics may have (Kinnie and Swart 2012; Vandenberhge, Bentein and Stinglhamber 2004). Interestingly, we find that individuals are about two times less hostile/more positive if they are the direct beneficiaries of a re-ranking of one of their own outlets, rather than when it was their field that benefitted from the re-grading. Social identity thus appears to be of lower importance than the expected return of high personal valence in influencing perceptions of rankings. These findings are consistent with previous research, which found that commitment to an individual career may be more important than other forms of commitment (Briscoe and Kinkelstein, 2009), particularly for academics. This suggests that in the consideration of ranking systems, the personal (the individual) trumps the professional (the field) in terms of generating hostility or positive views towards the ranking systems themselves.

There are a number of limitations to our research approach. First, the study is based upon a survey of scholars in a single country. However, it needs to be acknowledged that the UK has been in the vanguard of developing research assessment systems over more than two decades (Hicks, 2012). As such, the case of UK academics is useful to explore academics' attitudes towards rankings also in other contexts. Second, changes in the AJG were relatively modest in terms of journal 
upgrading and downgrading, and therefore many individuals were not directly affected by the changes. As such, our analysis is liable to be fairly conservative in the assessment of the impact on these changes on the attitudes of academics and should be viewed with caution. Moreover, we have very few downgraded journals and therefore we are not able to fully observe the potential hostility towards these decisions among our population. Third, while the AJG is well institutionalized within UK business schools, individuals who seek to publish in non-AJG journals may face exclusion. Although our study attempts to directly control for a possible weak alignment between an individual's research portfolio and the AJG itself, it may be that individuals who publish in non-AJG journals choose to relocate to other departments within their university. Fourth, we are unable to say how the changes in journal status shape changes in attitudes to the AJG, as we observe these attitudes at a single point of time. A future investigation with a longitudinal design would thus help address this question. Fifth, future research should explore how the critiques of the ranking system from strong disciplinary actors may help to alter the ranking system itself, reducing and mitigating the hostility to the ranking system among members of the aggrieved discipline. In effect, ranking systems are 'going concerns' that evolve in response to external and internal pressures. Greater research is required on the mechanics of these changes and how ranking systems seek to overcome hostility via change and alignment to the views of the people publishing in the journals they rank.

By bringing attention to how changes in a journal ranking system shape positive and negative attitudes by academics to the ranking system itself, we hope to help inform wider-ranging debates concerning journals lists and other forms of research assessment, and how these evaluation mechanisms are understood by the scholars upon which they are imposed. This debate is increasingly relevant as we observe a 
growing trend internationally toward utilizing more metric-based methods to evaluate the quality of research (Jappelli et al., 2017), with important implications for academics' careers. Satisfaction (vs. hostility) with a performance appraisal system has been shown to be an antecedent of actual performance (Kuvaas 2006). Although we do not claim that having more positive or hostile views of a ranking has implications on academics' performance, we do suggest that attitudes towards metricbased systems have implications on publication strategies in terms of chosen journals, as well as wider implications in terms of within-field debates, which may eventually help shape future versions of these rankings.

\section{REFERENCES}

Agrawal, V.K., Agrawal, V., and M. Rungtusanatham (2011) 'Theoretical and interpretation challenges to using the author affiliation index method to rank journals', Production and Operations Management, 20/2: 280-300.

Agyemang. G., and Broadbent, J. (2015) 'Management Control Systems and Research Management in Universities: An Empirical and Conceptual Exploration'. Accounting, Auditing and Accountability Journal, 28/7: 1-28.

Alvesson, M. and Sandberg, J. (2013) Constructing Research Questions: Doing Interesting Research. Los Angeles, CA: Sage.

ABS. (2015) Academic Journal Guide. London: Chartered Association of Business Schools.

Ashforth, B. E., and Mael, F. (1989) 'Social identity theory and the organization'. Academy of Management Review, 4/1: 20-39.

Adler, N. J., and Harzing, A.-W. (2009) 'When knowledge wins: Transcending the sense of and nonsense of academic rankings'. Academy of Management Learning \& Education, 8/1: 72-95.

Allen, R. S., Evans, W. R. and White, C. S. (2011) 'Affective organizational commitment and organizational citizenship behavior: examining the relationship through the lens of equity sensitivity'. Organization Management Journal, 8/4: 218228. 
Baden-Fuller, C., Ravazzolo, F. and T. Schweizer (2000). 'Making and Measuring Reputations: The Research Ranking of European Business Schools', Long Range Planning 33/5: 621-650

Ball, D. F. and Butler, J. (2004) The implicit use of business concepts in the UK Research Assessment Exercise. R\&D Management, 34/1: 87-97.

Baum, J.A. (2011) 'Free-riding on power laws: questioning the validity of the impact factor as a measure of research quality in organization studies'. Organization, 18/4: 449-466.

Beattie, V., and Goodacre, A. (2012). 'Publication records of accounting and finance faculty promoted to professor: Evidence from the UK', Accounting and Business Research, 42/2: 197-231.

Briscoe, J. P. and Finkelstein, L. M. (2009) 'The "new career" and organizational commitment: Do boundaryless and protean attitudes make a difference?' Career Development International, 14/3: 242-260.

Broadbent, J., (2010) 'The UK Research Assessment Exercise: Performance measurement and resource allocation'. Australian Accounting Review, 20/1: 14-23.

Bunderson, J. S. and Sutcliffe, K. M. (2002) 'Comparing alternative conceptualizations of functional diversity in management teams: Process and performance effects'. Academy of Management Journal, 45/5: 875-893.

By, R.T., Burnes, B. and Oswick, C. (2013) 'Creating a leading journal and maintaining academic freedom'. Journal of Change Management, 13/1: 1-8.

Chen, Y., Gupta, A. and Hoshower, L. (2006) 'Factors that motivate business faculty to conduct research: An expectancy theory analysis'. Journal of Education for Business, 81/4: 179-189.

Collini, S. (2008) Absent Minds: Intellectuals in Britain. Oxford: Oxford University Press.

Chatterji, M. and Seaman, P. (2006) 'Research Assessment Exercise results and research funding in the United Kingdom: A Comparative Analysis'. Education Economics, 14/3: 259-279.

De Rond, M. and Miller., A. N. (2005) 'Publish or perish bane or boon of academic life?'. Journal of Management Inquiry, 14/4: 321-329.

Dietz, J. S., and Bozeman, B. (2005) 'Academic careers, patents, and productivity: industry experience as scientific and technical human capital'. Research Policy, 34/3: 349-367.

Findlay, A. and Sparks, 1. (2010) 'The UK Research Assessment Exercise (RAE2008) and retail research output'. International Review of Retail, Distribution and Consumer Research, 20/5: 583-95. 
Giles, M.W. and J. C., Garand (2007) 'Ranking political science journals: Reputational and citational approaches'. PS: Political Science and Politics, 40/4: 74151.

Gioia, D.A. and Corley, K.G. (2002) 'Being good versus looking good: Business school rankings and the Circean transformation from substance to image'. Academy of Management Learning \& Education, 1/1: 107-120.

Harzing (2018) Harzing.com [on-line] https://harzing.com/resources/journal-qualitylist

Hazelkorn, E. (2007) 'Impact and influence of league tables and ranking systems on higher education Decision Making'. Higher Education Management and Policy, 19/2: 87-110.

Hazelkorn, E. (2008) 'Learning to live with league tables and ranking: The experience of institutional leaders'. Higher Education Policy, 21/2: 193-216.

Hazelkorn, E. (2009) 'Rankings and the battle for world-class excellence: Institutional strategies and policy choices'. Higher Education, Management and Policy, 21/1: 1-23.

Harman, G., (2000) 'Allocating research infrastructure grants in post-binary Higher Education systems: British and Australian approaches'. Journal of Higher Education Policy \& Management, 22/2: 111-126.

Henkel, M. (2005) 'Academic identity and autonomy in a changing policy environment'. Higher Education, 49/1-2: 155-176.

Hicks, D. (2012) 'Performance-based university research funding systems'. Research Policy, 41/2: 251-261.

Hicks, D., et al., I. (2015) 'Bibliometrics: The Leiden Manifesto for research metrics'. Nature, 520/7548: 429-431.

Hoepner, A.G.F., and Unerman, J. (2012) 'Explicit and implicit subject bias in the ABS journal quality guide'. Accounting Education, 21/1: 3-15.

Hussain, S. (2011) 'Food for thought on the ABS academic journal quality guide'. Accounting Education, 20/6: 545-559.

Hussain, S. (2012) 'Further food for thought on the ABS guide'. Accounting Education, 21/1: 17-22.

Hussain, S. (2015) 'Journal list fetishism and the 'sign of 4' in the ABS guide: A question of trust?’ Organization, 22/1: 119-138.

Jappelli, T., Nappi, and Torrini, R. (2017) 'Gender effects in research evaluation'. Research Policy, 46/5: 911-924. 
Khazragui, H., and Hudson, J. (2014) 'Measuring the benefits of university research: impact and the REF in the UK'. Research Evaluation, 24/1: 51-62.

Kinman, G. and Wray, S. (2016) 'Work-related wellbeing in UK higher education'. London: University and College Union.

Kinnie, N. and Swart, J. (2012) 'Committed to whom? Professional knowledge worker commitment in cross-boundary organizations'. Human Resource Management Journal, 22/1: 21-38.

Kuvaas, B. (2006) 'Performance appraisal satisfaction and employee outcomes: mediating and moderating roles of work motivation.' The International Journal of Human Resource Management, 17/3: 504-522.

Lawrence P. (2008) 'Lost in publication: how measurement harm science.' Ethics in Science and Environmental Politics, 8: 9-11.

Landis, R.S., Beal, D.J. and Tesluk, P.E. (2000) 'A comparison of approaches to forming composite measures in structural equation models.' Organizational Research Methods, 3/2: 186-207.

Lepine, J. A., Podsakoff, N. P. and Lepine, M. A. (2005) 'Explanation for inconsistent relationships among stressors and performance'. Academy of Management Journal, 48/5: 764-775.

Macdonald, S. and Kam, J., (2007) 'Ring a ring O' roses: Quality journals and Gamesmanship in Management Studies'. Journal of Management Studies, 44/4: 640655.

Mañana-Rodríguez, G. (2015) 'A critical review of SCImago Journal \& Country Rank.' Research Evaluation, 24/4: 343-354.

Mingers, J. and Willmott, H. (2013) 'Taylorizing business school research: On the 'one best way' performative effects of journal ranking lists'. Human Relations, 66/8: 1051-1073.

Morris, H., Harvey, C., and Kelly, A. (2009) 'Journal rankings and the ABS Journal Quality Guide', Management Decision, 47: 1441-51.

Morris, H., Harvey, C., Kelly, A., and M. Rowlinson (2011) 'Food for thought? A rejoinder on peer-review and RAE2008 evidence', Accounting Education, 20/6: 561573.

Newton, D. P. (2010) 'Quality and peer review of research: An adjudicating role for editors'. Accountability in Research, 17/3: 130-145.

Northcott, D., and Linacre S. (2010) 'Producing spaces for academic discourse: The impact of Research Assessment Exercises and journal quality rankings'. Australian Accounting Review, 20/1: 38-54. 
Perry, J. L., Engbers, T. A. and Jun, S. Y. (2009) 'Back to the Future? Performancerelated pay, empirical research, and the perils of persistence'. Public Administration Review, 69/1: 39-51.

Peeters, S. L. and van den Bos, K. (2008) 'When fairness is especially important: Reactions to being inequitably paid in communal relationships'. Social Justice Research, 21/1: 86-105.

Piercy, N., (2000) 'Why it is fundamentally stupid for a business school to try to improve its Research Assessment Score'. European Journal of Marketing, 34/1-2: 2735 .

Podsakoff, P. M., Mackenzie, S. B., Lee, J. Y., and Podsakoff, N. P. (2003) 'Common method bias in behavioral research: A critical review of the literature and recommended remedies'. Journal of Applied Psychology, 88/5: 879-903.

Porter, L. W., and Lawler, E. E. (1968) Managerial attitudes and performance. Homewood, IL: Irwin.

Pritchard, R. D., Dunnette, M. D., and Jorgenson, D. O. (1972) 'Effects of perceptions of equity and inequity on worker performance and satisfaction'. Journal of Applied Psychology, 56/1: 75-94

Reinstein, A. and T.G. Calderon (2006) 'Examining accounting department's rankings of the quality of accounting journals', Critical Perspectives on Accounting, 17/4: 457-90.

Rijcke, S. D., Wouters, P. F., Rushforth, A. D., Franssen, T. P., and Hammarfelt, B. (2016) Evaluation practices and effects of indicator use-a literature review. Research Evaluation, 25/2: 161-169.

Stewart, J. (2005) 'The UK research assessment exercise.' Human Resource Development International, 8/4:489-94.

Tajfel, H. and Turner, J. C. (1979) An integrative theory of intergroup conflict. In W. G. Austin \& S. Worchel (Eds.), The Social Psychology of Intergroup Relations. Monterey, CA: Brooks-Cole, pp.33-37.

Tytherleigh, M., Webb, C., Cooper, C., and Ricketts, C. (2005) 'Occupational stress in UK higher education institutions: A comparative study of all staff categories'. Higher Education Research \& Development, 24/5: 41-61.

Walker, J., Fenton, E., Salter, A., and Salandra, R. (2018) What influences business academics' use of the Association of Business Schools' (ABS) list? Evidence from a survey of UK academics, British Journal of Management, 00, 1-18, doi: 10.1111/1467-8551.12294

Williams, K., and Grant, J. (2018) 'A comparative review of how the policy and procedures to assess research impact evolved in Australia and the UK'. Research Evaluation, 27/2: 93-105. 
Willmott, H. (2011) 'Journal list fetishism and the perversion of scholarship: reactivity and the ABS list'. Organization, 18/4: 429-442.

Vandenberghe, C., Bentein, K., and Stinglhamber, F. (2004) 'Affective commitment to the organization, supervisor, and work group: Antecedents and outcomes'. Journal of Vocational Behavior, 64/1: 47-71.

Vogel, R., Hattke, F., \& Petersen, J. (2017). Journal rankings in management and business studies: What rules do we play by? Research Policy, 46/10: 1707-1722

Voss, C. (2010). 'Reflections on the state of OM'. POMS Chronicle, 17/1: 11-12.

Vroom, V. H. (1964) Work and motivation. San Francisco, CA: Jossey-Bass.

Van der Stede, W. A., Young, S. M., \& Chen, C. X. (2005). Assessing the quality of evidence in empirical management accounting research: The case of survey studies. Accounting, organizations and society, 30(7-8), 655-684. 
TABLE 1

Evaluation of Business School Research in the UK

\section{Research Excellence \\ Framework (REF) 2014}

\section{Academic Journal Guide}

(AJG)

\begin{tabular}{|c|c|c|}
\hline Consists of & $\begin{array}{l}\text { A national research assessment } \\
\text { system organized by the UK } \\
\text { government agency. The quality } \\
\text { of research is assessed in terms } \\
\text { of 'rigour, significance and } \\
\text { originality' based on the peer } \\
\text { review panels }\end{array}$ & $\begin{array}{l}\text { A journal list, based on a mix of } \\
\text { metrics and expert assessment. } \\
\text { Published in waves over the last } \\
10 \text { years by the Chartered } \\
\text { Association of Business Schools } \\
\text { (ABS) (independent/private) }\end{array}$ \\
\hline Purpose & $\begin{array}{l}\text { Rewards research performance } \\
\text { with funding based on the } \\
\text { quality of the publications } \\
(65 \%) \text {, research impact }(20 \%) \\
\text { and research environment }(15 \%)\end{array}$ & $\begin{array}{l}\text { Informs individuals' and } \\
\text { Business Schools' decision- } \\
\text { making about the value of } \\
\text { different research outputs, } \\
\text { influencing workload, hiring and } \\
\text { probationary systems }\end{array}$ \\
\hline $\begin{array}{l}\text { Level of } \\
\text { Assessment }\end{array}$ & $\begin{array}{l}\text { By units of assessment, or } \\
\text { subject level }\end{array}$ & $\begin{array}{l}\text { By individuals, journal level to } \\
\text { proxy individual's output } \\
\text { quality. }\end{array}$ \\
\hline Timing & Once every six to seven years & Updated every three years \\
\hline Ranking & 1-4 star & 1-4 star \\
\hline
\end{tabular}

Note: Further details relating to the REF 2014 are found at https://www.ref.ac.uk/2014/. The methodology for AJG list and the list itself can be accessed at https://charteredabs.org/academicjournal-guide-2015/. 
TABLE 2

Comparison of Output from Institutions from the REF (2014) \& RAE (2010) classified using the ABS (2010) Ranking

RAE Entry

\begin{tabular}{cccccc}
\hline ABS & $\begin{array}{c}\text { Top 5 } \\
(\%)\end{array}$ & $\begin{array}{c}5 \text { to 20 } \\
(\%)\end{array}$ & $\begin{array}{c}21 \text { to } 50 \\
(\%)\end{array}$ & $\begin{array}{c}\text { Greater than } \\
50(\%)\end{array}$ & Overall \\
\hline 1-star & 1.5 & 4.4 & 8.3 & 16.5 & 8.1 \\
2-star & 13.1 & 19.0 & 27.1 & 37.5 & 25.2 \\
3-star & 43.0 & 48.2 & 43.8 & 33.7 & 43.0 \\
4-star & 28.0 & 23.1 & 18.0 & 11.5 & 19.3 \\
World Elite & 14.4 & 5.3 & 2.8 & 0.7 & 4.4 \\
Journals & & & & & \\
\hline \% of 4-star & 42.4 & 28.3 & 20.8 & 12.3 & 23.8 \\
\cline { 2 - 6 } $\mathrm{N}$ & 1,136 & 3,783 & 3,545 & 2,436 & 10,900 \\
\hline
\end{tabular}

REF Entry REF 2014

\begin{tabular}{cccccc}
\hline ABS & $\begin{array}{c}\text { Top 5 } \\
(\%)\end{array}$ & $\begin{array}{c}5 \text { to 20 } \\
(\%)\end{array}$ & $\begin{array}{c}21 \text { to 50 } \\
(\%)\end{array}$ & $\begin{array}{c}\text { Greater than } \\
50(\%)\end{array}$ & Overall \\
\hline 1-star & 0.9 & 1.0 & 0.9 & 3.2 & 2.0 \\
2-star & 3.3 & 5.7 & 12.0 & 16.4 & 12.2 \\
3-star & 25.4 & 57.4 & 61.0 & 58.1 & 55.9 \\
4-star & 41.1 & 35.8 & 22.7 & 22.3 & 24.3 \\
$\begin{array}{c}\text { World Elite } \\
\text { Journals }\end{array}$ & 29.3 & 10.5 & 3.5 & 5.0 & 5.6 \\
\hline $\begin{array}{c}\text { \% of 4-star } \\
\text { N }\end{array}$ & 70.4 & 46.3 & 26.2 & 27.2 & 30.0 \\
\hline
\end{tabular}

Source: RAE (2008) and REF (2014) returns classified using the ABS (2010) journal classification. Note: RAE (2008) is composed to the Accounting and Finance and Business and Management units of assessment which were merged in the REF (2014). Comparison excludes non-journal outputs and those not captured by the ABS guide which equates to less $5 \%$ of the outputs submitted to the research evaluation exercise. 
TABLE 3

Hostility towards the Academic Journal Guide (proportion of responses on a 5-point scale)

\begin{tabular}{|c|c|c|c|}
\hline & $\begin{array}{l}\text { Disagree/Strongly } \\
\text { Disagree }\end{array}$ & Sometimes & $\begin{array}{l}\text { Agree/Strongly } \\
\text { Agree }\end{array}$ \\
\hline \multicolumn{4}{|l|}{ Negative views (Hostility) } \\
\hline $\begin{array}{l}\text { Shifts research efforts away from debates } \\
\text { that researchers would like to contribute } \\
\text { to }\end{array}$ & 10.8 & 20.8 & 68.5 \\
\hline Fosters a 'research monoculture' & 10.9 & 20.7 & 68.4 \\
\hline $\begin{array}{l}\text { Rewards journals that strive to 'imitate a } \\
\text { US-oriented model of scholarship' }\end{array}$ & 10.1 & 17.9 & 72.0 \\
\hline $\begin{array}{l}\text { Encourages researchers to focus on issues } \\
\text { that are only of interest to other } \\
\text { academics rather than } \\
\text { practitioners/policy-makers }\end{array}$ & 15.8 & 24.8 & 59.4 \\
\hline Promotes 'low risk' research & 18.4 & 23.6 & 58.0 \\
\hline $\begin{array}{l}\text { Leads to 'technically well-executed but } \\
\text { boring research' }\end{array}$ & 20.7 & 32.6 & 46.6 \\
\hline \multicolumn{4}{|l|}{ Positive views (positively inclined) } \\
\hline $\begin{array}{l}\text { Helps researchers to make judgments } \\
\text { about the quality of research being } \\
\text { undertaken by a researcher in their field }\end{array}$ & 10.9 & 20.7 & 68.4 \\
\hline $\begin{array}{l}\text { Helps researchers to make judgments } \\
\text { about the quality of research being } \\
\text { undertaken by a researcher outside their } \\
\text { field }\end{array}$ & 29.8 & 19.7 & 50.5 \\
\hline Helps research efforts to get recognized & 31.1 & 25.6 & 43.3 \\
\hline $\begin{array}{l}\text { Motivates academics to try to achieve } \\
\text { higher research quality }\end{array}$ & 35.1 & 23.5 & 41.4 \\
\hline
\end{tabular}

Note: Five-point scale has been simplified into three groups for expositional purposes. 
TABLE 4. Descriptive Statistics and Correlation Matrix

\begin{tabular}{|c|c|c|c|c|c|c|c|c|c|c|c|c|c|c|c|c|c|c|c|c|c|}
\hline & Variables & Mean & s.d. & 1 & 2 & 3 & 4 & 5 & 6 & 7 & 8 & 9 & 10 & 11 & 12 & 13 & 14 & 15 & 16 & 17 & 18 \\
\hline 1 & $\begin{array}{c}\text { Mean } \\
\text { (Negative Views) }\end{array}$ & 3.74 & 0.83 & 1 & & & & & & & & & & & & & & & & & \\
\hline 2 & $\begin{array}{c}\text { Mean } \\
\text { (Positive Views) }\end{array}$ & 3.07 & 0.99 & $-0.42^{*}$ & 1 & & & & & & & & & & & & & & & & \\
\hline 3 & "New" 3 & 0.15 & 0.36 & -0.04 & 0.01 & 1 & & & & & & & & & & & & & & & \\
\hline 4 & "Old" 3 & 0.09 & 0.28 & 0.02 & 0.01 & 0.05 & 1 & & & & & & & & & & & & & & \\
\hline 5 & "New" 4 & 0.18 & 0.38 & $-0.10^{*}$ & $0.08 *$ & $0.09 *$ & $0.11^{*}$ & 1 & & & & & & & & & & & & & \\
\hline 6 & "Old" 4 & 0.03 & 0.17 & -0.03 & -0.02 & $0.09 *$ & $0.13^{*}$ & -0.01 & 1 & & & & & & & & & & & & \\
\hline 7 & $\begin{array}{l}\text { Changes within the } \\
\text { Field that focal } \\
\text { individual considers } \\
\text { their primary field of } \\
\text { expertise }\end{array}$ & 0.25 & 0.17 & $-0.05^{*}$ & 0.05 & 0.03 & $0.08^{*}$ & 0.01 & $0.08 *$ & 1 & & & & & & & & & & & \\
\hline 8 & Included in REF 2014 & 0.54 & 0.50 & -0.08 & -0.05 & $0.12^{*}$ & $0.15^{*}$ & $0.11^{*}$ & $0.23 *$ & $0.07 *$ & 1 & & & & & & & & & & \\
\hline 9 & Citations & 1.10 & 1.37 & -0.09 & 0.02 & 0.03 & $0.21^{*}$ & 0.05 & $0.23 *$ & $0.14 *$ & $0.18^{*}$ & 1 & & & & & & & & & \\
\hline 10 & $\begin{array}{l}\text { SNIP - publication } \\
\text { over REF period }\end{array}$ & 13.35 & 27.05 & $-0.18 *$ & $0.06 *$ & $0.19 *$ & $0.27 *$ & $0.10^{*}$ & $0.30 *$ & $0.17 *$ & $0.25 *$ & $0.43^{*}$ & 1 & & & & & & & & \\
\hline 11 & Professor & 0.34 & 0.47 & $-0.06^{*}$ & 0.02 & $0.12^{*}$ & $0.11^{*}$ & $0.15^{*}$ & $0.18^{*}$ & $0.10^{*}$ & 0.34 * & $0.38^{*}$ & $0.35 *$ & 1 & & & & & & & \\
\hline 12 & Associate Professor & 0.36 & 0.48 & 0.03 & -0.03 & -0.02 & 0.01 & -0.02 & $-0.07 *$ & -0.02 & $-0.10^{*}$ & $-0.16^{*}$ & $-0.15^{*}$ & $-0.34 *$ & 1 & & & & & & \\
\hline 13 & Lecturer & 0.30 & 0.46 & 0.02 & 0.01 & $-0.11^{*}$ & $-0.13 *$ & $-0.14 *$ & $-0.12 *$ & $-0.08^{*}$ & $-0.25 *$ & $-0.22^{*}$ & $-0.20 *$ & $-0.37 *$ & $-0.49 *$ & 1 & & & & & \\
\hline 14 & Gender & 0.58 & 2.77 & -0.02 & 0.05 & 0.01 & $0.06^{*}$ & 0.02 & $0.07 *$ & 0.03 & $0.09 *$ & $0.13^{*}$ & $0.15^{*}$ & $0.17 *$ & $-0.08^{*}$ & -0.09 & 1 & & & & \\
\hline 15 & Academic age & 12.2 & 8.50 & 0.03 & -0.04 & $0.1^{*}$ & -0.03 & $0.16^{*}$ & 0.05 & 0.02 & 0.05 & 0.2 & 0.38 & $0.41 *$ & $0.42 *$ & -0.11 & $0.2 *$ & 1 & & & \\
\hline 16 & $\begin{array}{l}\text { Obtained PhD in } \\
\text { North America }\end{array}$ & 0.06 & 0.23 & $-0.16^{*}$ & 0.02 & 0.04 & 0.03 & 0.03 & 0.04 & 0.05 & $0.06 *$ & $0.09 *$ & 0.11 * & 0.02 & -0.03 & 0.02 & $0.06^{*}$ & 0.00 & 1 & & \\
\hline 17 & $\begin{array}{l}\text { Proportion of output } \\
\text { published in journals } \\
\text { included in the } \\
\text { ABS/AJG lists }\end{array}$ & 0.61 & 0.49 & -0.03 & 0.00 & -0.01 & $0.07 *$ & $-0.11 *$ & 0.01 & -0.05 & $0.10^{*}$ & $0.08^{*}$ & $0.07 *$ & $0.11 *$ & 0.00 & 0.02 & -0.02 & -0.02 & -0.05 & 1 & \\
\hline 18 & $\begin{array}{c}\text { Overall Rank of } \\
\text { Institution in REF } \\
2014\end{array}$ & 35.03 & 24.33 & $0.09 *$ & -0.04 & $-0.07 *$ & -0.15 & -0.03 & $-0.18 *$ & -0.01 & $-0.19 *$ & $-0.20^{*}$ & $-0.25 *$ & $-0.12^{*}$ & $0.12^{*}$ & 0.00 & $-0.12^{*}$ & $-0.15 *$ & $-0.13 *$ & -0.03 & 1 \\
\hline 19 & $\begin{array}{l}\text { Involved in } \\
\text { construction of } \\
\text { ABS/AJG }\end{array}$ & 0.06 & 0.24 & -0.05 & $0.09^{*}$ & 0.01 & 0.05 & 0.04 & $0.09 *$ & 0.05 & $0.08^{*}$ & $0.17^{*}$ & $0.18^{*}$ & $0.24 *$ & $-0.10^{*}$ & $-0.14 *$ & $0.09 *$ & 0.03 & 0.03 & -0.02 & -0.07 \\
\hline
\end{tabular}

* indicates a pairwise correlation is significant at the $5 \%$ level. Correlations between the field 22 dummies and other variables are omitted due to space considerations. 
TABLE 5

Generalized Least Squares Regressions Predicting Negative Views towards the Academic Journal Guide

\begin{tabular}{|c|c|c|c|c|c|c|c|c|c|c|c|}
\hline & Variables & 1 & & 2 & & 3 & & 4 & & 5 & \\
\hline \multicolumn{12}{|l|}{ Independent Variables } \\
\hline Changes in the ranking of journals & "New" 3 & & & 0.021 & $(0.74)$ & 0.021 & $(0.74)$ & 0.022 & $(0.75)$ & 0.028 & $(0.90)$ \\
\hline where an individual has published & "Old" 3 & & & 0.058 & $(1.53)$ & 0.058 & $(1.53)$ & 0.057 & (1.50) & 0.056 & (1.48) \\
\hline & "New" 4 & & & $-0.075^{* *}$ & (2.08) & $-0.075 * *$ & $(2.08)^{* *}$ & $-0.076 * *$ & (2.10) & $-0.077^{* * *}$ & (2.08) \\
\hline & "Old" 4 & & & -0.128 & $(1.47)$ & -0.128 & $(1.47)$ & -0.129 & $(1.49)$ & -0.143 & $(1.60)$ \\
\hline Change in field & $\begin{array}{l}\text { Changes in proportion of 4-star output } \\
\text { within the field }\end{array}$ & & & & & -0.040 ** & (2.14) & $-0.035 * *$ & (2.13) & $0.034 * *$ & (2.12) \\
\hline \multicolumn{12}{|l|}{ Control Variables } \\
\hline $\begin{array}{l}\text { Included in National Research } \\
\text { Evaluation }\end{array}$ & Included in REF 2014 & $-0.104 * *$ & (2.08) & $-0.095^{*}$ & (1.89) & $-0.095 *$ & (1.89) & $-0.081^{* *}$ & (1.98) & $-0.095 *$ & (1.85) \\
\hline Academic Influence & $\begin{array}{l}\text { Citations } \\
\text { SNIP - publication over REF period }\end{array}$ & 0.000 & $(1.45)$ & $-0.006 * * *$ & (3.35) & $-0.005 * * *$ & (3.24) & & & & \\
\hline \multirow{3}{*}{$\begin{array}{l}\text { (Ref. SNIP (age adjusted) - } \\
\text { publication over REF period - Q4) }\end{array}$} & SNIP - publication over REF period - Q1 & & & & & & & $0.202 * *$ & (2.36) & $0.207 * * *$ & (2.13) \\
\hline & SNIP - publication over REF period - Q2 & & & & & & & $0.142 *$ & (1.85) & $0.150^{*}$ & (1.89) \\
\hline & SNIP - publication over REF period - Q3 & & & & & & & 0.052 & $(0.50)$ & -0.054 & $(0.51)$ \\
\hline Academic Rank & Associate Professor & 0.091 & (1.37) & 0.079 & $(1.20)$ & 0.079 & $(1.20)$ & 0.083 & (1.26) & 0.067 & (0.99) \\
\hline (Ref. Professor) & Lecturer & $0.157 * *$ & (2.13) & $0.148 * *$ & (2.02) & $0.148 * * * *$ & $(2.02) * *$ & $0.155 * *$ & (2.11) & $0.144 *$ & (1.91) \\
\hline Gender (Ref. female) & Gender & $-0.147 * * *$ & (3.18) & $-0.145 * * *$ & (3.15) & $-0.145 * * *$ & (3.15) & $-0.145 * * *$ & (3.16) & $-0.157 * * *$ & (3.31) \\
\hline Academic age & Number of years in academia & $0.015^{* * * *}$ & (4.01) & $0.014 * * *$ & (3.94) & $0.014 * * *$ & (3.94) & $0.014 * * *$ & (3.99) & $0.014 * * *$ & (3.81) \\
\hline Obtained PhD in North America & North America & $-0.426 * * *$ & (4.02) & $-0.423 * * *$ & (3.98) & $-0.423^{* * * *}$ & (3.98) & $-0.424 * * *$ & (4.00) & $-0.429 * * *$ & (4.02) \\
\hline Alignment to List & $\begin{array}{l}\text { Proportion of output published in journals } \\
\text { included in the AJG list }\end{array}$ & & & & & & & & $(0.02)$ & 0.009 & $(0.18)$ \\
\hline Institutional Environment & Overall Rank of Institution in REF 2014 & 0.002 & (1.68) & 0.001 & (1.47) & 0.001 & $(1.47)$ & 0.001 & $(1.50)$ & 0.001 & $(1.41)$ \\
\hline Involved & Involved in construction of AJG & -0.068 & $(0.60)$ & -0.055 & $(0.48)$ & -0.055 & $(0.48)$ & -0.054 & $(0.47)$ & -0.072 & $(0.57)$ \\
\hline Constant & & $3.840^{* * * *}$ & (32.82) & $3.850^{* * * *}$ & (33.14) & $3.887^{* * * *}$ & (31.98) & $4.052 * * * *$ & (31.89) & $4.073^{* * * *}$ & (31.30) \\
\hline Field Fixed-Effects & & YES & & YES & & YES & & YES & & YES & \\
\hline Log likelihood & & -1438.17 & & -1432.80 & & -1432.80 & & -1346.88 & & -1260.19 & \\
\hline
\end{tabular}

Note: $\quad N=1,409$ for models 1-4 that include all fields. $N=1,085$ for models 5 that excluded General Management, Sector and Social Sciences. Coefficient reported. Zstatistics in parentheses. Significant variables in highlighted in bold. *** $\mathrm{p}<0.01, * * \mathrm{p}<0.05, * \mathrm{p}<0.1$. 
TABLE 6

Generalized Least Squares Regressions Predicting Positive Views towards the Academic Journal Guide

\begin{tabular}{|c|c|c|c|c|c|c|c|c|c|c|c|}
\hline \multirow{3}{*}{ Independent } & \multirow[t]{3}{*}{ Variables } & \multicolumn{2}{|l|}{1} & \multicolumn{2}{|l|}{2} & \multicolumn{2}{|l|}{3} & \multirow[t]{2}{*}{4} & \multicolumn{3}{|c|}{5} \\
\hline & & & & & & & & & & & \\
\hline & & & & & & & & & & & \\
\hline Changes in the ranking & "New" 3 & & & -0.029 & $(0.86)$ & -0.029 & $(0.86)$ & -0.045 & $(0.75)$ & -0.062 & $(1.60)$ \\
\hline of journals & "Old" 3 & & & -0.026 & $(0.53)$ & -0.026 & $(0.53)$ & -0.032 & $(1.50)$ & -0.026 & $(0.53)$ \\
\hline where an individual & "New" 4 & & & $0.075^{* *}$ & (2.02) & $0.075^{* * *}$ & (2.02) & $0.061 * *$ & (2.10) & $0.058^{* * *}$ & (2.45) \\
\hline has published & "Old" 4 & & & 0.036 & $(0.75)$ & 0.036 & $(0.75)$ & 0.424 & $(1.49)$ & 0.450 & $(0.76)$ \\
\hline Change in field & $\begin{array}{l}\text { Changes in proportion of } 4 \text {-star output } \\
\text { within the field }\end{array}$ & & & & & $0.057^{* *}$ & (2.31) & $0.062^{* * *}$ & (2.13) & $\mathbf{0 . 0 5 3}^{*}$ & (1.88) \\
\hline Control Variables & & & & & & & & & & & \\
\hline $\begin{array}{l}\text { Included in National } \\
\text { Research Evaluation }\end{array}$ & Included in REF 2014 & $0.177 * * *$ & (2.95) & $0.159 * * *$ & (2.66) & $0.159^{* *}$ & (2.66) & $0.142 * *$ & (1.98) & $0.123 *$ & (1.83) \\
\hline Academic Influence & $\begin{array}{l}\text { Citations } \\
\text { SNIP }\end{array}$ & 0.000 & $(0.80)$ & & & & & & & & \\
\hline (Ref SNIP (age & $\begin{array}{l}\text { SNIP - publication over REF period } \\
\text { SNIP - publication RFF period - O1 }\end{array}$ & & & $0.005^{* *}$ & (1.98) & -0.005 & (1.43) & -0036 & $(0.40)$ & -0.007 & $(0.08)$ \\
\hline adjusted) - & SNIP - publication over REF period - Q2 & & & & & & & 0.108 & $(1.06)$ & 0.123 & $(1.17)$ \\
\hline $\begin{array}{l}\text { publication over REF } \\
\text { period - Q4) }\end{array}$ & SNIP - publication over REF period - Q3 & & & & & & & $0.311 * *$ & (2.23) & $0.323 * *$ & (2.24) \\
\hline Academic Rank & Associate Professor & -0.019 & $(0.23)$ & -0.001 & $(0.01)$ & 0.025 & $(0.01)$ & 0.059 & $(0.70)$ & 0.062 & $(0.71)$ \\
\hline (Ref. Professor) & Lecturer & 0.040 & $(0.44)$ & 0.060 & $(0.65)$ & -0.009 & $(0.65)$ & $0.186 *$ & (1.84) & $0.222 * *$ & (2.09) \\
\hline Gender (Ref. female) & Gender & 0.027 & $(0.44)$ & 0.025 & $(0.41)$ & 0.011 & $(0.41)$ & -0.021 & $(0.35)$ & 0.006 & $(0.09)$ \\
\hline Academic age & Number of years in academia & $-0.009 * * *$ & (2.04) & $-0.009 * * *$ & (1.95) & $0.000 * * *$ & (1.95) & $-0.011 * * *$ & (2.15) & $-0.008 * * *$ & (1.61) \\
\hline $\begin{array}{l}\text { Obtained PhD in North } \\
\text { America }\end{array}$ & North America & 0.019 & $(0.17)$ & 0.011 & $(0.10)$ & 0.382 & $(0.10)$ & 0.011 & $(0.09)$ & 0.011 & $(0.09)$ \\
\hline Alignment to List & $\begin{array}{l}\text { Proportion of output published in journals } \\
\text { included in the AJG list }\end{array}$ & & & & & & & -0.036 & $(0.55)$ & 0.000 & $(0.01)$ \\
\hline $\begin{array}{l}\text { Institutional } \\
\text { Environment }\end{array}$ & Overall Rank of Institution in REF 2014 & 0.000 & $(0.35)$ & 0.000 & $(0.22)$ & 0.000 & $(0.22)$ & 0.000 & $(0.03)$ & 0.399 & (3.34) \\
\hline Involved & Involved in construction of AJG & $0.398 * * *$ & (3.64) & $0.382 * * *$ & (3.51) & $0.382 * * *$ & (3.51) & $0.442 * * *$ & $(4.00)$ & -0.072 & $(0.57)$ \\
\hline Constant & & $2.944 * * *$ & (18.65) & $2.934 * * *$ & (18.48) & $2.848 * * *$ & (16.95) & $2.887 * * *$ & (15.74) & $2.850 * * *$ & $(\mathbf{1 5 . 2 2})$ \\
\hline Field Fixed-Effects & & YES & & YES & & YES & & YES & & YES & \\
\hline Log likelihood & & -1691.08 & & -1683.48 & & -1683.48 & & -1559.56 & & -1260.18 & \\
\hline
\end{tabular}

Note: $\quad N=1,409$ for models 1-4 that include all fields. $N=1,085$ for models 5 that excluded General Management (including ethics) CSR, Sector and Social Sciences.

Coefficient reported. Z-statistics in parentheses. Significant variables in highlighted in bold. $* * * p<0.01, * * \mathrm{p}<0.05, * \mathrm{p}<0.1$. 
